\title{
HS071, A New Furan-type Cytotoxic Metabolite from Streptomyces sp. HS-HY-071
}

\author{
Jidong Wang, Hui Zhang, Xiaohu Yang, Yue Zhou, Haibin Wang, Hua Bai
}

Received: June 25, 2008 / Accepted: September 15, 2008

(C) Japan Antibiotics Research Association

\begin{abstract}
Investigation of the bioactive metabolites from the soil-derived actinomycete, Streptomyces sp. HS-HY071, a new furan-type antibiotic, HS071 (1), was isolated. Its structure was established as methyl 4-hydroxymethyl-2pentylfuran-3-carboxylate on the basis of extensive 1D and 2D NMR and MS spectral analysis. It exhibited in vitro activity against HCT-116 cell with an $\mathrm{IC}_{50}$ of $18.2 \mu \mathrm{g} / \mathrm{ml}$.
\end{abstract}

Keywords Streptomyces sp. HS-HY-071, HS071, cytotoxic

\section{Introduction}

In order to search for new natural antitumor bioactive metabolites, we have screened thousands of microbial strains isolated from the soil samples collected from Xishuangbanna in Yunnan Province. Among them, 257 strains were found having good activities against some lines of tumor cell. In the further chemical study of a strain HSHY-071, a new furan-type cytotoxic antibiotic, HS071 (1) was isolated. This paper reports the basic taxonomy and fermentation of the strain HS-HY-071 and the isolation, structure elucidation and biological property of $\mathbf{1}$.

H. Wang (Corresponding author), J. Wang, H. Zhang, X. Yang, Y. Zhou, H. Bai: Zhejiang Hisun Pharmaceutical Co., Ltd., Taizhou, Zhejiang 318000, China, E-mail: hbwang@hisunpharm. com

\section{Materials and Methods}

\section{Microorganism}

The producing organism designated HS-HY-071 was isolated from a soil sample collected at Xishuangbanna, Yunnan, China. Strain HS-HY-071 was deposited in the Pharmaceutical Research Culture Collection, Zhejiang Hisun Group Co., Ltd., with the name of Streptomyces sp. HS-HY-071 under accession No: HSAS071.

\section{Taxonomy}

The International Streptomyces Project (ISP) media recommended by Shirling and Gottlieb [1] were used to investigate the culture and physiological characteristics. Cultures were routinely observed after the incubation for two weeks at $28^{\circ} \mathrm{C}$. All carbon-sources for carbonutilization tests were filter-sterilized and tested at the concentrations recommended by Shirling and Gottlieb [1] and Williams et al. [2]. Cell wall analysis was performed by the method of Hasegawa and Takizawa [3]. Extraction of genomic DNA and 16S rDNA gene amplification were carried out according to Pitcher et al. [4] 16S rDNA sequences were compared with those of other bacterial $16 \mathrm{~S}$ rDNA sequences available in the GenBank database.

\section{Fermentation}

Strain HS-HY-071 was inoculated into a 500-ml flask containing $100 \mathrm{ml}$ of seed culture medium consisting of (\%) soluble starch 1.5 , glucose 0.5 , peptone 0.5 , yeast extract $0.5, \mathrm{NaCl} 0.05, \mathrm{MgSO}_{4} \cdot 7 \mathrm{H}_{2} \mathrm{O} 0.05, \mathrm{CaCO}_{3} 0.1, \mathrm{pH}$ 7.2. Incubation was carried out at $28^{\circ} \mathrm{C}$ for 3 days on a rotary shaker operating at $250 \mathrm{rpm}$. Then a $7.0 \%$ of seed culture broth was cultured in a 20-liter of fermentation at $28^{\circ} \mathrm{C}$ for 6 days, the medium is consisted of $(\%)$ soluble starch 4.0 , glucose 0.5 , soybean meal 2.5 , yeast extract 0.5 , 
Table 1 Cultural characteristics of strain HS-HY-071

\begin{tabular}{|c|c|c|c|c|}
\hline Medium & Growth & Aerial mycelium & Reverse color & Soluble pigment \\
\hline Tryptone-yeast extract agar (ISP-1) & Very good & Light gray & Blue grey & None \\
\hline Yeast extract-malt agar (ISP-2) & Very good & Purple black & Purple black & None \\
\hline Oatmeal agar (ISP-3) & Very good & White & Light brown & None \\
\hline Inorganic salt-starch agar(ISP-4) & Good & Light yellow & Pale yellow & None \\
\hline Glycerol-asparagine agar (ISP-5) & Good & Pale yellow & Yellow green & None \\
\hline YMS & Very good & Light gray & Black brown & None \\
\hline
\end{tabular}

$\mathrm{NaCl} 0.05, \mathrm{MgSO}_{4} \cdot 7 \mathrm{H}_{2} \mathrm{O} 0.05, \mathrm{CaCO}_{3} 0.1, \mathrm{pH}$ 7.2.

\section{Isolation and Physico-chemical Characterization}

After fermentation for 6 days, the cultured broth was centrifugated to separate mycelial cake and supernatant. The mycelial cake was extracted with $\mathrm{MeOH}$ and the supernatant was extracted with Diaion HP-20 and eluted with $95 \% \mathrm{EtOH}$. The combined methanol soluble and the EtOH eluates were evaporated to give the crude extract. Fractionations of the crude extract by silica gel column chromatography, Sephadex LH-20 and reversed-phase HPLC successively gave compound $\mathbf{1}$.

\section{General}

UV spectra was obtained on a Varian CARY 300 BIO spectrophotometer; IR spectra was recorded on a Nicolet Magna FT-IR 750 spectrometer $\left(v_{\max }\right.$ in $\left.\mathrm{cm}^{-1}\right) ;{ }^{1} \mathrm{H}$ - and ${ }^{13} \mathrm{C}-\mathrm{NMR}$ spectra were measured with a Bruker DRX-400 (400 MHz for ${ }^{1} \mathrm{H}$ and $100 \mathrm{MHz}$ for ${ }^{13} \mathrm{C}$ ) spectrometer. Chemical shifts are reported in parts per million $(\delta)$, using residual $\mathrm{CHCl}_{3}\left(\delta_{\mathrm{H}} 7.26 \mathrm{ppm}\right)$ and $\mathrm{CDCl}_{3}\left(\delta_{\mathrm{C}} 77.0 \mathrm{ppm}\right)$ as internal standards, with coupling constants $(J)$ in $\mathrm{Hz} .{ }^{1} \mathrm{H}-$ and ${ }^{13} \mathrm{C}-\mathrm{NMR}$ assignments were supported by ${ }^{1} \mathrm{H}-{ }^{1} \mathrm{H}$ COSY, HMQC and HMBC experiments. The ESI-MS and HRESI-MS spectra were taken on a Q-TOF Micro LC-MSMS mass spectrometer. RP-HPLC was conducted on an Agilent 1100 series. Commercial silica gel (Qing Dao Hai Yang Chemical Group Co., 100 200 and 200 300 mesh) was used for column chromatography.

\section{Biological Assays}

Human colon carcinoma cell line HCT-116 was routinely cultured in DMEM containing $10 \%$ calf serum at $37^{\circ} \mathrm{C}$ for 4 hours, in a humidified atmosphere of $5 \% \mathrm{CO}_{2}$ incubator. The adherent cells at their logarithmic growth stage were digested, and were inoculated onto 96-well culture plate at a density of $1.0 \times 10^{4} /$ well for the determination of proliferation. Test samples were added to the medium, and incubation was continued for 72 hours. Coloration substrate, cell counting kit-8 (CCK-8, Dojindo), was added to the medium followed by further incubation for 3 hours. Absorbance at $450 \mathrm{~nm}$ with a $600 \mathrm{~nm}$ reference was measured thereafter. Media and DMSO control wells, in which compound was absent, were included in all the experiments in order to eliminated the influence of DMSO. The inhibitory rate of cell proliferation was calculated by the following formula:

Growth inhibition $(\%)=\left[\mathrm{OD}_{\text {control }}-\mathrm{OD}_{\text {treated }}\right] / \mathrm{OD}_{\text {control }} \times 100$ The cytotoxicity of compound on tumor cells was expressed as $\mathrm{IC}_{50}$ values (the drug concentration reducing by $50 \%$ the absorbance in treated cells, with respect to untreated cells) and was calculated by LOGIT method.

\section{Results and Discussion}

\section{Taxonomy of the Producing Strain}

The strain HS-HY-071 is a Gram-positive actinomycete which formed well-developed and branching substrate mycelium and aerial mycelium, but fragmentation of the substrate mycelium was not observed. Good growth was observed on ISP-1, ISP-2, ISP-3 and YMS. The best medium for the culture of this strain was ISP-2, on which it grew abundantly (Table 1). The long spore chains were of the Spirales-type with smooth surface. Mature spore were oval with a diameter of $(0.5 \sim 0.7) \times(0.7 \sim 0.9) \mu \mathrm{m}$. Physiological characteristics and carbon utilization of the strain are summarized in Table 2. Diaminopimelic acid (DAP) analysis showed the presence of LL-DAP in the peptidoglycan [5]. Furthermore, a BLAST search of $16 \mathrm{~S}$ rDNA sequences in the Genbank database showed the highest similarity of Streptomyces minoensis. The above results support the identification of this strain as a species of the genus Streptomyces, and named Streptomyces sp. HS-HY-071.

\section{Fermentation and Isolation}

Streptomyces sp. HS-HY-071 was grown at $28^{\circ} \mathrm{C}$ in a 20 - 
Table 2 Morphological and physiological characteristics and carbon utilization of strain HS-HY-071

\begin{tabular}{lc}
\hline Spore chain morphology & Spirales \\
Spore surface & Smooth \\
Spore dimensions $(\mu \mathrm{m})$ & $(0.5 \sim 0.7) \times(0.7 \sim 0.9)$ \\
Temperature range for growth $\left({ }^{\circ} \mathrm{C}\right)$ & $15 \sim 36$ \\
Optimal temperature for growth $\left({ }^{\circ} \mathrm{C}\right)$ & $26 \sim 30$ \\
Production of $\mathrm{H}_{2} \mathrm{~S}$ & + \\
Liquefaction of gelatin & - \\
Degradation of casein & - \\
Hydrolysis of starch & + \\
Reduction of nitrate & + \\
Carbon utilization & \\
D-Glucose & + \\
D-Xylose & + \\
L-Arabinose & + \\
L-Rhamnose & + \\
D-Fructose & - \\
D-Mannitol & + \\
D-Sucrose & + \\
D-Galactose & + \\
\hline
\end{tabular}

liter of fermentation. After 6 days, the cultured broth $(9.0$ liters) was centrifugated to separate mycelial cake and supernatant. The mycelial cake was extracted with $\mathrm{MeOH}$ (3.0 liters) and the supernatant was extracted with Diaion HP-20 and eluted with 95\% EtOH. The combined $\mathrm{MeOH}$ soluble and the $\mathrm{EtOH}$ eluates were evaporated to give $11.5 \mathrm{~g}$ of crude extract. This crude extract was subjected to a silica gel column and eluted with petrol ether $-\mathrm{Me}_{2} \mathrm{CO}$ from 19:1 1:1. The active fractions showing inhibitory activity against HCT-116 cell were collected and evaporated to afford $550 \mathrm{mg}$ of a residue. The residue was also subjected to a Sephadex LH-20 column and eluted with $\mathrm{MeOH}$ and the active fraction was further separated by semi-preparative HPLC using a reversed-phase column (Zorbax SB-C18, $5.0 \mu \mathrm{m}, 250 \times 9.4 \mathrm{~mm}$ i.d) and a solvent of $75 \% \mathrm{MeOH} / \mathrm{H}_{2} \mathrm{O}$ with a flow rate of $1.5 \mathrm{ml} /$ minute at a room temperature. The eluates were monitored with a photodiode array detector at $220 \mathrm{~nm}$. Compound $\mathbf{1}$ was eluted at $12.3 \mathrm{~min}$ to give pure $\mathbf{1}(9 \mathrm{mg})$ as a viscous colorless oil.

\section{Physico-chemical Characterization and Structure Determination}

Compound 1 (Fig. 1) was obtained as a viscous colorless oil with UV (EtOH) $\lambda_{\max } \mathrm{nm} 203$ ( $\varepsilon$ 6619) and 249 ( $\varepsilon$ 5643). It is soluble in $\mathrm{MeOH}, \mathrm{CH}_{3} \mathrm{CN}, \mathrm{Me}_{2} \mathrm{CO}, \mathrm{CH}_{2} \mathrm{Cl}_{2}$, and $\mathrm{CHCl}_{3}$, but is insoluble in $\mathrm{H}_{2} \mathrm{O}$. The physico-chemical properties of $\mathbf{1}$ are shown in Table 3. Its molecular formula
Table 3 Physico-chemical properties of HSO71 (1)

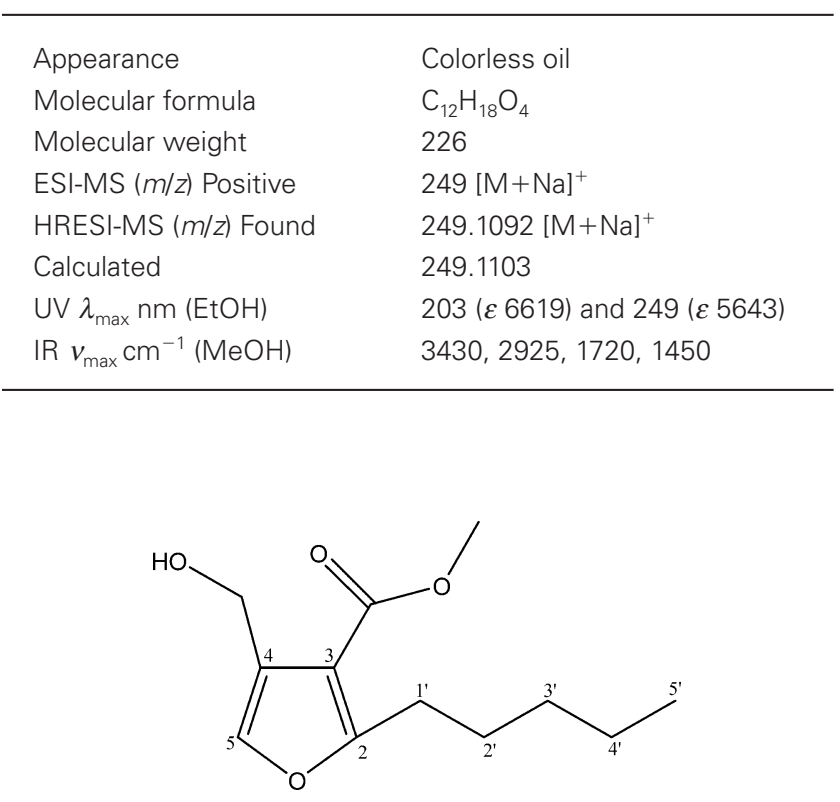

Fig. 1 The structure of HSO71 (1)

Table $4{ }^{1} \mathrm{H}$ - and ${ }^{13} \mathrm{C}$-NMR data of HSO71 (1) in $\mathrm{CDCl}_{3}$

\begin{tabular}{crl}
\hline No. & ${ }^{13} \mathrm{C}$ (mult) & \multicolumn{1}{c}{${ }^{1} \mathrm{H}$} \\
\hline 2 & $165.0(\mathrm{~s})$ & \\
3 & $112.0(\mathrm{~s})$ & \\
4 & $125.8(\mathrm{~s})$ & \\
5 & $138.3(\mathrm{~d})$ & $7.24(1 \mathrm{H}, \mathrm{s})$ \\
$1^{\prime}$ & $28.2(\mathrm{t})$ & $2.93(2 \mathrm{H}, \mathrm{t}, \mathrm{J}=7.5 \mathrm{~Hz})$ \\
$2^{\prime}$ & $27.6(\mathrm{t})$ & $1.66(2 \mathrm{H}, \mathrm{m})$ \\
$3^{\prime}$ & $31.3(\mathrm{t})$ & $1.31(2 \mathrm{H}, \mathrm{m})$ \\
$4^{\prime}$ & $22.3(\mathrm{t})$ & $1.33(2 \mathrm{H}, \mathrm{m})$ \\
$5^{\prime}$ & $13.9(\mathrm{q})$ & $0.90(3 \mathrm{H}, \mathrm{t}, J=7.5 \mathrm{~Hz})$ \\
$\mathrm{CH}_{2} \mathrm{OH}$ & $55.7(\mathrm{t})$ & $4.56(2 \mathrm{H}, \mathrm{br} \mathrm{s})$ \\
$\mathrm{CO}^{\prime}$ & $165.8(\mathrm{~s})$ & \\
$\mathrm{CH}_{3} \mathrm{O}$ & $51.7(\mathrm{q})$ & $3.88(3 \mathrm{H}, \mathrm{s})$ \\
\hline
\end{tabular}

was established as $\mathrm{C}_{12} \mathrm{H}_{18} \mathrm{O}_{4}$ by HRESI-MS $m / z 249.1092$ $[\mathrm{M}+\mathrm{Na}]^{+}$, calc for 249.1103 . The IR spectrum of $\mathbf{1}$ revealed an ester carbonyl absorption at $1720 \mathrm{~cm}^{-1}$ and a hydroxy absorption at $3430 \mathrm{~cm}^{-1}$, respectively. The ${ }^{1} \mathrm{H}-$ NMR spectrum of 1 showed an olefinic proton at $\delta 7.24$ $(1 \mathrm{H}, \mathrm{s})$, a methoxy signal at $\delta 3.88(3 \mathrm{H}, \mathrm{s})$, and an aliphatic methyl at $\delta 0.90(3 \mathrm{H}, \mathrm{t})$. Its ${ }^{13} \mathrm{C}-\mathrm{NMR}$ and DEPT 135 data (Table 4) indicated four $s p^{2}$ quaternary carbons at $\delta 165.8$, $165.0,125.8,112.0$, a methylene bonding with oxygen at $\delta$ 55.7, and four aliphatic methylenes at $\delta 31.3,28.2,27.6$ and 22.3 , respectively. 


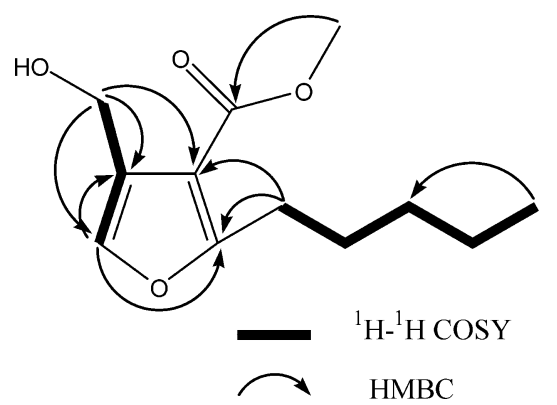

Fig. 2 The ${ }^{1} \mathrm{H}-{ }^{1} \mathrm{H}$ COSY and $\mathrm{HMBC}$ correlations observed in compound $\mathbf{1}$

The gross structure of $\mathbf{1}$ was established mainly based on the ${ }^{1} \mathrm{H}-{ }^{1} \mathrm{H}$ COSY and HMBC correlations (Fig. 2). In the ${ }^{1} \mathrm{H}-{ }^{1} \mathrm{H}$ COSY (spectrum), the crossing signals between $\delta_{\mathrm{H}}$ 2.93 and 1.66, 1.66 and 1.31 connected from $\mathrm{C}-1^{\prime}-\mathrm{C}-3^{\prime}$, and the correlation of $\delta_{\mathrm{H}} 0.90$ and 1.33 connected from $\mathrm{C}$ $4^{\prime}-\mathrm{C}-5^{\prime}$. Furthermore, the three bonds HMBC correlation from $\mathrm{H}_{3}-5^{\prime}$ to $\mathrm{C}-3^{\prime}$ assigned the pentyl moiety from $\mathrm{C}-1^{\prime}$ C-5'. In the HMBC spectrum, the observed correlated signals of $\delta_{\mathrm{H}} 7.24 / \delta_{\mathrm{C}} 125.8(\mathrm{~s}), 55.7(\mathrm{t}), 112.0(\mathrm{~s}), 165.0(\mathrm{~s})$ indicated the presence of a furan ring, and the correlations of $\delta_{\mathrm{H}} 4.56$ and $\delta_{\mathrm{C}} 138.3(\mathrm{~d}), 125.8(\mathrm{~s}), 112.0(\mathrm{~s})$ showed a hydroxymethyl bonding at position 4 of the furan ring. The pentyl group connected to C-2 confirmed by the HMBC signals berween $\delta_{\mathrm{H}} 2.93$ and $\delta_{\mathrm{C}} 165.0(\mathrm{~s}), 112.0(\mathrm{~s})$. The HMBC correlation of the methoxy signal at $\delta_{\mathrm{H}} 3.88$ and $\delta_{\mathrm{C}}$ 165.8 showed the $\delta_{\mathrm{C}} 165.8$ was an ester carbonyl and it was placed at C-3. Thus, the structure of $\mathbf{1}$ was completely elucidated and it was methyl 4-hydroxymethyl-2pentylfuran-3-carboxylate.

\section{Biological Activities}

We examined the inhibitory activity of compound $\mathbf{1}$ against the growth of human colon carcinoma cell line HCT-116 using the CCK-8 colorimetric method as described in the materials and methods section. Compound 1 dosedependently inhibited the growth of HCT-116 cells with an $\mathrm{IC}_{50}$ value of $18.2 \mu \mathrm{g} / \mathrm{ml}$.

\section{References}

1. Shirling EB, Gottlieb D. Methods for characterization of Streptomyces species. Int J Syst Bacteriol 16: 313-340 (1966)

2. Williams ST, Goodfellow M, Alderson G. Genus Streptomyces Waksman and Henrici 1943. In Bergey's Manual of Sysmatic Bacteriology. Vol. 4, Ed., Williams ST., pp. 2452-2492, Williams \& Wilkins, Baltimore (1989)

3. Hasegawa T, Takizawa M, Tanida S. A rapid analysis for chemical group of aerobic actinomycetes. J Gen Appl Microbial 29: 319-322 (1983)

4. Pitcher DD, Sauders NA, Owen RJ. Rapid extraction of bacterial genomic DNA with guanidinium thiocyanate. Lett Appl Microbiol 8: 151-156 (1989)

5. Lechevalier MP, Lechevalier H. Chemical composition as a criterion in the classification of aerobic actinomycetes. Int $\mathrm{J}$ Syst Bacteriol 20: 435-443 (1970) 